\title{
EL ESTADO DE MEXICO, PIONERO DEL LIBERALISMO EN MEXICO
}

\author{
Oliva Castro Orozco \\ Dirección de Estudios Históricos. INAH, \\ Cronista Municipal de Metepec, Edo. de México \\ Margarita Loera Chávez y Peniche \\ Dirección de Estudios Históricos. INAH, \\ Cronista Municipal de Calimaya, Edo. de México y miembro del SNI
}

El triunfo del liberalismo en México es un fenómeno histórico que no puede desprenderse de la comprensión cabal de lo que fue la Iglesia católica durante la Colonia y el siglo XIX.

Los fueros y privilegios que la Corona española otorgó a aquella institución religiosa durante el reina- do de los Habsburgo (1571-1700), le llevaron a adquirir tal poder, que bien puede decirse, que se tomó en el eje que controló el todo del conjunto social novo- hispano. En el rubro de lo económico, la Iglesia llegó a ser propietaria de cuantiosos bienes materiales: haciendas y ranchos agro-ganaderos, ingenios azucareros, propiedades urbanas y capital líquido que adquirió, por un lado, a través de donaciones piadosas, legados testamentarios, capellanías y obras pías, y por el otro, por recepciones que impuso de manera obligatoria como fueron los diezmos y las obvenciones. ${ }^{1}$ Obviamente, esta bonanza material la convirtió de manera natural en prestamista y socia de empresarios agrícolas y ganaderos, comerciantes y mineros. En otras palabras, en una institución cuyo poder material ejercía un fuerte control en las diversas actividades de la economía colonial.

En el plano de lo hegemónico su influencia no fue menor. Al ostentarse como representante de lo divino en la tierra, su fuerza moral resultó absoluta. Conducía espiritual e ideológicamente a la sociedad, detentando la labor educativa desde las más sencillas escuelas de los pueblos, hasta las universidades y centros de enseñanza superior; ${ }^{2}$ controlaba la conducta social pues la ley estaba impregnada por su normatividad moral y su cumplimiento era velado por los tribunales de la Santa Inquisición, por la injerencia de los religiosos

1 Asunción Lavrín, "The role of the numeries in the economy of New Spain in the Eighteenth Century”, Hispanic American Historical Review, XLVI, núm. 4, octubre de 1919.

2 Martín Quirarte, El problema religioso en México, México, INAH., 1967 
en los tribunales pueblerino s, y por supuesto, por la reprobación social al incumplimiento de la misma.

También ejerció control pleno sobre las instancias de asistencia social como fueron los hospitales, los hospicios y los centros de beneficencia en general. ${ }^{3}$ En resumen, quien no vivía en concordancia y bajo la sujeción de la Iglesia no tenía cabida en la sociedad novohispana. Inclusive hasta la población conquistada llegó a tener a la institución eclesiástica como centro rector de su vida. Una vez consolidada la empresa de evangelización durante el siglo XVI, los indios re- construyeron su mundo dentro de los patrones establecidos por los españoles, pero con una fuerte herencia de sus culturas prehispánicas. ${ }^{4}$ En esta nueva forma, lo religioso, claro que en marco de la apariencia cristiana, siguió siendo el centro que permeaba el todo de su vida social, política, económica y cultural. En el seno de las comunidades campesinas la institución eclesiástica lo controlaba todo, inclusive las tierras de carácter corporado que con el tiempo fueron siendo entregadas a los santos a través de las cofradías y las mayordomías. ${ }^{5}$

Hacia el siglo XVIII, cuando la Casa de Borbón ocupó la Corona española, tuvo bien claro que para tomar en sus manos el control de sus colonias en América, era necesario limitar el poder de la Iglesia. Entonces, bajo el influjo de las nuevas corrientes ilustradas, que ya en Europa habían llevado a profundos cambios sociales en distintos países, se llevaron a efecto las llamadas Reformas Borbónicas en la Nueva España. Con tales medidas, fueron afectados todos los órdenes: el monopolio de los comerciantes de la ciudad de México, la minería, el sector agrario, la organización política, la educación y en términos generales, la ideología. En materia eclesiástica, se llevó a efecto todo un programa que bien podría reconocerse como las primeras políticas de desamortización y limitación de privilegios, en distintos órdenes. Por ejemplo, en 1737 por un acuerdo entre Felipe IV y el Papado, se ordenó que los bienes de la Iglesia cubrieran impuestos. Tres décadas después, Carlos III dictó Real Cédula prohibiendo que la Iglesia siguiera adquiriendo bienes, y en 1767 ordenó la expulsión de los jesuitas, por entonces, la orden religiosa más próspera y poderosa. Carlos IV continuó con la obra reformista, ya sin acuerdo con el Papa; así, en 1795 dictó leyes sobre fueros eclesiásticos, ordenando la intervención de jueces laicos en los tribunales del clero. Poco después, se expidieron otras en las que se obligó al clero a cubrirle al Estado,

3 Ibidem.

4 Margarita Loera-Chávez y Peniche, Economia Campesina Indigena durante la Colonia, México, Instituto Nacional Indigenista, 1982.

5 Ibidem. 
el15 por ciento de todos los bienes que se amortizaran. En 1798 se decretó la venta de bienes eclesiásticos de algunos establecimientos religiosos y y se indicó que el producto de las enajenaciones debía ponerse en una Real Caja de Amortización con un interés del 3 por ciento. Por último, Carlos IV dio una disposición más radical que fue expedida con el nombre de Real Cédula de Consolidación de Vales Reales en 1804. En ella se determinó que se recogieran los capitales de los juzgados de capellanías y de obras pías y se enviaran a España; la Corona a cambio, se obligó a reconocer dichos capitales y a pagar los réditos de los mismos. ${ }^{6}$

Sin embargo, este trastrocamiento lejos de derivar en una mejoría global del orden social, benefició sólo a los intereses hispanos, en Nueva España más bien creó serios descalabros económicos, sobre todo en la agricultura. Por lo tanto, el descontento no se hizo esperar. Tales medidas empero, impregnaron de inquietudes a grupos medios de la sociedad colonial, quienes las vieron con simpatía, pero pensado que el quitar los privilegios a la Iglesia, era algo que de lograrse podría derivar en un verdadero reacomodo interno en estas tierras y no del beneficio de una Corona distante como estaba ocurriendo. Se sentaba así, un precedente muy temprano a las ideas que después enarbolarían los grupos liberales en la Constitución de 1857.

Durante el movimiento de Independencia, otros avances de lo que después sería el liberalismo mexicano, se vieron plasmados en los Elementos Constitucionales de Ignacio López Rayón de agosto de 1811; en los famosos Sentimientos de la Nación de José María Morelos y Pavón de 1813, y en el decreto constitucional para la libertad de América mexicana, mejor conocido como la Constitución de Apatzingán, expedido el14 de octubre de 1814. Todos estos documentos pueden catalogarse como básicos para la construcción del proyecto que sostendría la estructura del México independiente. En todos ellos se aprecia una fuerte influencia de pensadores franceses como Rousseau y Montesquieu, sin embargo poco o prácticamente nulo es el avance en materia de desamortización de bienes eclesiásticos o libertad de credos religiosos. Es decir, que en esta etapa no se retornaron en realidad los cambios en materia eclesiástica emprendidos con las Reformas Borbónicas.?

6 Romeo Flores Caballero, La contrarrevolución de independencia. Los españoles en la vida politica, social y económica de México, (1804-1838), México, El Colegio de México, 1969.

7 Felipe Tena Ramírez, Leyes fundamentales de México, 1808-1957, México, Porrúa, 1957; Mario Colín, Mario Rosales Betancourt, Trayectoria constitucional del Estado de México, México, Biblioteca Enciclopédica del Estado de México, 1974; Oliva Castro Orozco, "Pérdida de privilegios eclesiásticos durante la primera república federal 1824-1835. (El caso del Estado de México)", Tesis de Licenciatura en la UNAM, México, Inédita, 1995. 
Menos aún se retomó en el Plan de Iguala elaborado por Iturbide en $1821,{ }^{8}$ lo cual no es de llamar la atención, tomando en cuenta que los ideólogos del movimiento insurgente no fueron, a pesar del abrazo de Acatempan, entre Iturbide y Guerrero, los que lograron realmente el triunfo de la Independencia de México.

Una parte de los criollos que apoyaron la causa de Iturbide, representaban un grupo resistente a cualquier cambio que afectara al viejo orden colonial en el que la Iglesia señoreaba todo. Así, en el caos de la posguerra y en la necesidad de aprender a ser una nación independiente se inició una feroz batalla entre los que propugnaban por conservar el antiguo régimen y los que buscaban el cambio y sabían muy bien que para lograrlo había que empezar golpeando los privilegios de la Iglesia. El reto no fue fácil, porque la sociedad en pleno, y aun ellos mismos, eran profundos creyentes en la fe cristiana, la afectación de los muchos intereses e instancias de poder que encubría la Iglesia, implicaba tiempo, trabajo, y un cambio ideológico que derivó en enfrentamientos de muy variado tipo, que llegaron a la violencia constante que signó al siglo XIX mexicano.

Después de la Independencia fue, pues, cuando aquellos que para entonces apenas mal dibujaban lo que posteriormente sería el Partido Liberal, iniciaron realmente el reto de cambiar en México las herencias coloniales de los Habsburgo. Los intentos emprendidos con las Reformas Borbónicas fueron acciones que provenían de fuera y cuya búsqueda miraba más bien hacia el beneficio de España, y los que se dieron durante el movimiento insurgente, apenas dibujaban el cambio que se logró hasta 1867 cuando con el triunfo definitivo del liberalismo mexicano se hizo cumplir la constitución de 1857. Acaso por ello los orígenes y procesos en que se gestó tan importante cambio en la historia de nuestro país y que datan de las primeras décadas de su vida independiente, muy poco han sido tomadas en cuenta. ${ }^{9}$ Creemos sin embargo, que no puede entenderse el liberalismo mexicano si no se considera su raíz y su base pionera de desarrollo, que fue el Estado de México. Curiosamente allí, en un lugar caracterizado por su reticencia al cambio y con una

8 En donde se sigue considerando a la religión católica apostólica y romana como única sin tolerancia de ninguna otra.

9 Robert J. Knowlton, Los bienes del Clero y la Reforma mexicana, 1856-1910, México, Fondo de Cultura Económica, 1985; Jan Bazant, Los bienes de la Iglesia en México, 18561875, México, El Colegio de México, 1984; Agustín Cué Cánovas, Constitución y liberalismo, México, Secretaría de Educación Pública, 1963; Mílada Bazant de Saldaña, La desamortización de los bienes de la Iglesia en Toluca durante la reforma (1856-1875), México, Biblioteca Enciclopédica del Estado de México, 1979. 
tendencia conservadora mayoritaria que quería preservar las normas y organización política colonial, se promulgó en 1827 la constitución más avanzada en materia liberal del momento y en 1833 se aplicaron las reformas más tempranas contra la institución eclesiástica. De tal suerte, que bien puede afirmarse que el Estado de México fue el sitio donde más tempranamente se sentaron las bases que dieron cuerpo al liberalismo triunfante de la segunda mitad del Siglo XIX Mexicano. ${ }^{10}$

Si tomamos en cuenta que para lograr el triunfo del Federalismo en nuestro país, la entidad que nos ocupa tuvo que ceder a la nación su capital natural, es decir la ciudad de México, y que no fueron pocos los descalabros internos que como consecuencia tuvo que enfrentar, era obvio que sus habitantes se hubiesen, como de hecho lo hicieron en un principio, inclinado por la posición centralista que los sectores conserva- dores y los propietarios de grandes haciendas en la entidad enarbolaban. ${ }^{11}$ ¿Cómo entender entonces que la posición liberal hubiese logrado, precisamente en ese entorno geopolítico imponer su ideología en forma tan temprana?

En realidad, la posición federalista como principio rector del Estado mexicano, no fue aceptado por la mayor parte de los oriundos de la entidad en un primer momento, como sucedió con otros estados de la república. Más que anuencia, podría considerarse un acto forzado a funcionar en tal sistema, aunque más tarde fue una estrategia política de un grupo concreto con ideas progresistas.

Detrás de lo anteriormente señalado, obviamente había realidades históricas sin Las cuales no puede entenderse tal proceso. Primero hay que tomar en cuenta que la posición del territorio en cuestión. Se trataba y se trata del entorno geográfico de la ciudad de México; o sea del centro rector de la vida política económica y aún religiosa del país. Era, además, zona nodal por su gran extensión territorial y su alta densidad demográfica. ${ }^{12}$ Así, el tenerle

10 Mario Colín, Mario Rosales Betancourt, Op. cit.; Charles W. Macunne Jr., El Estado de México y la Federación Mexicana, 1823-1835, México, Fondo de Cultura Económica, 1978; Lorenzo de Zavala, Ensayo histórico de las revoluciones de México, desde 1808 hasta 1830, México, Fondo de Cultura económica, 1985; Carlos Herrejón Peredo, Historia del Estado de México, México, UAEM, 1985; Antonio Huitrón H., La erección del Estado de México, México, Libros de México, 1974.

11 Margarita Loera-Chávez, Murmullos de antiguos muros. Las construcciones del siglo XVI que se conservan en el Estado de México, México, Gobierno del Estado de México, INAH, 1994; Oliva Castro Orozco, Op. cit.

12 Peter Gerhard, Geografía histórica de la Nueva España 1519-1821, México, UNAM, 1986. 
política e ideológicamente controlada era, por lo tanto, clave para cualquier grupo que intentara imponerse en el resto de la nación y el incipiente grupo liberal pareció comprenderlo muy bien. Por eso, algunos de sus integrantes a pesar de no ser oriundos de su suelo, lograron acceder al poder local, incluso al ejecutivo estatal e impusieron su ideología en el Congreso Constituyente que dio cuerpo a la primera Constitución Estatal en 1827.

En realidad la urbe capital y el territorio que después constituyó el Estado de México, se desarrollaron durante la Colonia dentro del esquema simbiótico que impone toda relación ciudad campo. Ya desde el siglo XVI los grandes propietarios que controlaban la economía regional, operaban y ejercían el dominio de la zona desde el cabildo de la ciudad de México. Hemos probado en otros trabajos, como al consolidarse las pequeñas oligarquías locales de tipo hispano hacia finales de la primera centuria virreinal, éstas quedaron subordinadas a aquellos grandes propietarios. ${ }^{13}$

Cuando nació la República en el México independiente, los poderes federales y estatales compartieron al inicio el mismo espacio urbano de la ciudad de México. No es de extrañar, en consecuencia, que quienes ocuparon los primeros cargos públicos estatales fueran habitantes de la metrópoli. La verdad es que bastó ser propietario de algún inmueble en el territorio de la entidad; ${ }^{14}$ situación que no es de llamar la atención, pues un buen número de dueños de haciendas y ranchos, sin ser necesariamente miembros de las grandes oligarquías nacionales, tenían sus residencias permanentes en la ciudad de México. En otras palabras, si por un lado el Estado de México fue la región más estratégica de controlar, por el otro el acceso a su estructura de poder local, no fue difícil para gentes oriundas de otros lados, especialmente para los residentes de la ciudad de México.

Es por eso que José María Luis Mora y Lorenzo de Zavala entre otros, impusieron la huella del liberalismo primario en la historia de la legislación mexiquense, a pesar de que no fueron oriundos de su territorio, si siquiera de su entonces capital natural, la ciudad de México.

Su colaboración dentro de la política de la entidad fue la siguiente: Mora destacó en el campo de la teoría, con su participación en los Congresos estatales, y Zavala en la ejecución y práctica de las ideas, así fue como contribuyeron a

13 Margarita Loera-Chávez, Murmullos de antiguos muros. Las construcciones del siglo XVI que se conservan en el Estado de México, México, Gobierno del Estado de México, INAH, 1994.

14 Charles W. Macunne Jr., Op. cit.; Marta Baranda y Lía García Verástegui, Estado de México, una historia compartida, México, Gobierno del Estado de México, 1987. 
llevar a cabo una política liberal que condujo a la modificación y suspensión de privilegios eclesiásticos que se plasmaron en la Constitución promulgada el 14 de febrero de 1827 en dicha entidad.

En esta Constitución además de mencionarse por primera vez las garantías individuales, también se asentaron las bases fundamentales en materia de garantías sociales. En ella se respetaron las disposiciones más importantes y sobresalientes del pensamiento progresista del momento, por ejemplo se señaló, antes de que lo hicieran los otros Estados de la República y aun el gobierno federal, que, quedan prohibidas en el Estado, para lo sucesivo, la adquisición de bienes raíces por manos muertas". ${ }^{15}$ Otra importante restricción al poder de la Iglesia, que planteó también la Constitución de 1827, fue considerar que el hacer votos eclesiásticos era motivo para perder la ciudadanía. También se mencionaba en ella la prohibición para que los obispos, gobernadores de mitras y los vicarios generales fueran diputados. ${ }^{16}$

Lorenzo de Zavala contribuyó en gran medida para que el Estado de México fuera pionero en lo relativo a la nacionalización y desamortización de los bienes eclesiásticos, puesto que al ser nombrado gobernador decretó la nacionalización de bienes misioneros de Filipinos que consistían en las haciendas La Chica y la Grande en Texcoco, San Pedro Tejalpa, Guadalupe y San Diego en Toluca, que sostenían el hospicio de los misioneros de Asia y Filipinas en San Agustín de las Cuevas (Tlalpam). Nacionalización que no pudo llevarse a cabo hasta que fue nuevamente gobernador en $1833 .{ }^{17}$

Repartió tierras por un valor de medio millón de pesos entre más de 40 pueblos indígenas en el Valle de Toluca. Suprimió el impuesto de los productos manufacturados por los indios, y para aumentar el presupuesto del Estado decretó la "ley de ausentismo". Esta consistía en cobrar un impuesto a todo aquél propietario de tierras que viviera fuera de la república, así como que "los demás propietarios que habiendo salido de la República no volvieran a ella después de 4 años.... ${ }^{18}$ También propuso la fijación de un límite para la adquisición de tierras, con el fin de evitar su acumulación.

15 Arlículo 27 de la Constitución política del Estado de México de 1827.

16 Mario Colín, Constituciones del Estado de México. 1827, 1861, 1870,1917, Conmemoración del sesquicentenario de la erección del Estado de México, 1824-1974, México, Biblioteca Enciclopédica del Estado de México, 1974.

17 Marta Baranda y Lía García Verástegui (Comps), Marta Baranda y Lía García Verástegui (Comps), Estado de México, textos de su historia, T I y II, México, Gobierno del Estado de México, 1987.

18 Marta Baranda y Lía García Verástegui, Op. cit. 
Los realizadores de la Constitución de 1827 vislumbraron la gran importancia de los problemas que creaba el poder eclesiástico. De ahí que desde el Primer Congreso Constitucional del Estado de México en marzo de 1827, se enunció un camino para iniciar la reforma contra los privilegios de la institución eclesiástica.

Verbigracia, en el artículo primero se dijo que: "Se declaran pertenecientes al Estado de México todos los bienes que poseen en el mismo; los hospicios destina- dos para las Misiones Filipinas".

En el artículo segundo, se mencionaba que "Los que adquieran algunos en fraude de esta determinación, los perderán irremisiblemente, y las autoridades a que toque velarán exactamente su cumplimiento".

En el artículo tercero, se hablaba de lo siguiente: "de los fondos del Estado se mantendrán las iglesias que por cuenta de ellos se sostienen en él y se juzgue necesario que continúen”.

En el artículo cuarto, se decía "que a los religiosos comprendidos en el primer artículo se les ministrará por el gobierno, si residieran en los puntos del Estado que aquél designe, una pensión anual de cuatrocientos pesos cada uno para sus alimentos. ${ }^{19}$

Es evidente que estas determinaciones del gobierno estatal, se anticiparon con mucho a las leyes de desamortización de los bienes del clero llevadas a cabo con los constituyentes de 1857.

Dentro de este primer periodo federalista, los reformadores liberales centraron su atención y propugna- ron por la reforma del clero. Se abogaba abiertamente por la confiscación de los bienes de la Iglesia. Conforme las ideas liberales fueron ganando adeptos, empezó a surgir gradualmente una reforma contra el clero, que excedía considerablemente las propuestas relativamente limitadas que se habían debatido con anterioridad en relación a temas como el fuero eclesiástico. ${ }^{20}$

Así para 1833, el programa de los reformistas consistía básicamente en la supresión de privilegios eclesiásticos, lo que representaba una seria amenaza al poder económico de la Iglesia y un desafío a su autoridad y a sus libertades.

Después de largos meses de discusiones, contra los opositores a las reformas que querían efectuar los liberales, estos últimos lograron aplicar una serie de leyes encaminadas a disminuir el poder clerical, como por ejemplo las siguientes:

19 Marta Baranda y Lía García Verástegui (Comps), Op. cit.

20 Documentos del Congreso Constitucional del Estado de México, 1824, 1827, 1830,1835. Archivo de la Cámara de Diputados del estado de México. Toluca, México 
- 17 de agosto de 1833: Secularización de los misioneros de California.

- 31 de agosto de 1833: Confiscación de los misioneros filipinos.

- 14 de octubre de 1833: Cierre del Colegio de Sta. María de todos los Santos.

- 18 de octubre de 1833: Orden de venta en pública subasta de los bienes de los misioneros de San Camilo y Filipinos.

- 19 de octubre de 1833: Cierre de la Universidad de México.

- 24 de Octubre: Establecimiento de la Biblioteca nacional en el edificio que había pertenecido al Colegio de Sta. María de todos los Santos.

- 27 de octubre de 1833: Supresión de la obligación civil de pagar diezmos.

- 3 de noviembre de 1833: Supresión del nombra- miento de canonjías.

- 6 de noviembre de 1833: Supresión de la obligatoriedad civil de los votos eclesiásticos.

- 18 de noviembre de 1833: Suspensión de todas las ventas de bienes por las órdenes regulares.

- 17 de diciembre de 1833: nombramiento de curas para las parroquias vacantes.

- 24 de diciembre de 1833: Prohibición de todas las ventas de los bienes del clero. ${ }^{21}$

Estas leyes revelan las materias a las que los liberales concedían preferencia y en las que esperaban afirmar la influencia de la administración civil con exclusión de la eclesiástica. Así al llevar a cabo estas modificaciones dentro del plano eclesiástico, obvia- mente se le restaba poder económico, político y social a una institución que durante tres siglos lo había detentado sin límite.

Factores diversos intervinieron para que el programa impulsado por los reformadores del 33 no se llevara a su total realización. Entre ellos, las complicaciones políticas con los grupos que estaban en contra de las reformas propuestas y que contribuyeron a que los dirigentes reformadores de esta época no se sostuvieran en el poder el tiempo suficiente para llevar a cabo su programa liberal. Aún así, se sentó un precedente dentro de la evolución legislativa a nivel estatal y nacional que marcó un adelanto de 33 años dentro de la legislación. El hecho de no haberse anulado toda la legislación liberal de 1833-34 con el restablecimiento de la República Centralista, muestra hasta que punto había declinado la influencia del Clero y hasta que punto la lucha tenaz de aquellos primeros liberales había dado frutos.

El hecho de que se diera ese avance legislativo en el Estado de México, obedeció a varias razones que muestran una herencia histórica de gran tras-

21 Charles W. Macunne Jr., Op. Cit. 
cendencia, gracias a la cual esa entidad geográfica, además de brindar claras oportunidades para facilitar una acción definida por parte de los sectores liberales, era a su vez, un punto estratégico para que precisamente en ese sitio los liberales pusieran sus ojos de manera prioritaria.

Por eso, a pesar de los conflictos que tuvieron con el Gobierno nacional, originados básicamente por la pérdida de la ciudad de México, contradictoriamente hubo de manera paralela una alianza entre los sectores liberales que a nivel nacional detentaron el poder, y los que a nivel estatal lo hicieran también. El objetivo de la misma fue claramente el de dirigir su acción política hacia el resto del país, controlando su zona central y rectora: ${ }^{22}$

\section{BIBLIOGRAFÍA.}

Agustín Cué Cánovas, Constitución y liberalismo, México, Secretaria de Educación Pública, 1963.

Antonio Huitrón H., La erección del Estado de México, México, Libros de México, 1974.

Artículo 27 de la Constitución política del Estado de México de 1827. Asunción Lavrín, "The role of the numeries in the economy of New Spain in the Eighteenth Century", Hispanic American Historical Review, XLVI, núm. 4, octubre de 1919.

Carlos Herrejón Peredo, Historia del Estado de México, México, UAEM, 1985.

Documentos del Congreso Constitucional del Estado de México, 1824, 1827, 1830,1835. Archivo de la Cámara de Diputados del estado de México. Toluca, México.

Felipe Tena Ramírez, Leyes fundamentales de México, 1808-1957, México, Porrúa, 1957.

Jan Bazant, Los bienes de la Iglesia en México, 1856-1875, México, El Colegio de México, 1984.

Lorenzo de Zavala, Ensayo histórico de las revoluciones de México, desde 1808 hasta 1830, México, Fondo de Cultura Económica, 1985.

Margarita Loera-Chávez y Peniche, Economia Campesina Indigena durante la Colonia, México, Instituto Nacional Indigenista, 1982

22 El desglose minucioso de este trabajo que incluye debates de los Congresos y los continuos problemas entre los conservadores y los liberales puede verse en el trabajo de Oliva Castro Orozco, "Pérdida de privilegios eclesiásticos durante la primera república federal 18241835. (El caso del Estado de México) "Tesis de Licenciatura en la UNAM, y cuya coordinación y seguimiento académico estuvo a cargo de la Dra. Margarita Loera-Chávez. 
Margarita Loera-Chávez, Murmullos de antiguos muros. Las construcciones del Siglo XVI que se conservan en el Estado de México, México, Gobierno del Estado de México, INAH, 1994; Oliva Castro Orozco.

Margarita Loera-Chávez, Murmullos de antiguos muros. Las construcciones del Siglo XVI que se conservan en el Estado de México, México, Gobierno del Estado de México, INAH, 1994

Mario Colín, Constituciones del Estado de México. 1827, 1861, 1870, 1917, Conmemoración del sesquicentenario de la erección del Estado de México, 1824-1974, México, Biblioteca Enciclopédica del Estado de México, 1974.

Mario Colín, Mario Rosales Betancourt, Op. Cit.; Charles W. Macunne Jr., El Estado de México y la Federación Mexicana, 1823-1835, México, Fondo de Cultura Económica, 1978.

Mario Colín, Mario Rosales Betancourt, Trayectoria Constitucional del Estado de México, México, Biblioteca Enciclopédica del Estado de México, 1974.

Marta Baranda y Lía García Verástegui (Comps), Estado de México, textos de su historia, T I y II, México, Gobierno del Estado de México, 1987.

Marta Baranda y Lía García Verástegui (Comps), Op., cit.

Marta Baranda y Lía García Verástegui, Estado de México, una historia compartida, México, Gobierno del Estado de México, 1987.

Martín Quirarte, El problema Religioso en México, México, INAH, 1967.

Mílada Bazant de Saldaña, La desamortización de los Bienes de la Iglesia en Toluca durante la Reforma (1856-1875), México, Biblioteca Enciclopédica del Estado de México, 1979.

Oliva Castro Orozco, "Pérdida de privilegios eclesiásticos durante la primera república federal 1824-1835. (El caso del Estado de México) ", Tesis de Licenciatura en la UNAM, México, Inédita, 1995.

Oliva Castro Orozco, "Pérdida de privilegios eclesiásticos durante la primera república federal 1824-1835. (El caso del Estado de México)" Tesis de Licenciatura en la UNAM, y cuya coordinación y seguimiento académico estuvo a cargo de la Dra. Margarita Loera-Chávez.

Peter Gerhard, Geografia histórica de la Nueva España 1519-1821, México, UNAM, 1986.

Robert J. Knowlton, Los bienes del Clero y la Reforma mexicana, 1856-1910, México, Fondo de Cultura Económica, 1985.

Romeo Flores Caballero, La contrarrevolución de independencia. Los españoles en la vida política, social y económica de México, (1804-1838), México, El Colegio de México, 1969. 